\title{
Attitude and Knowledge of Occupational Therapy Professionals and Trainees about Sexual Rehabilitation of Persons with Disabilities
}

Anthony O. Jejelaye ${ }^{1 *}$, Olumide A. Olaoye ${ }^{1}$, Oluwatosin O. Oni ${ }^{1}$, Adeyemi S. Adejumobi ${ }^{1}$, Kehinde F. Olagunju ${ }^{1}$, Anne I. Emechete ${ }^{2}$

${ }^{1}$ Department of Medical Rehabilitation, Obafemi Awolowo University, Ile-Ife, Nigeria

${ }^{2}$ Obafemi Awolowo University Teaching Hospitals Complex, Ile-Ife, Osun State, Nigeria

\author{
DOI: $10.36348 /$ SJNHC.2019.v02i09.002 \\ | Received: 29.08.2019| Accepted: 05.09.2019 | Published: 11.09.2019 \\ *Corresponding author: Anthony O. Jejelaye
}

\section{Abstract}

Aim: The quality of care given by occupational therapists on sexual rehabilitation of persons with physical disabilities (PWDs) is influenced by their knowledge about, and attitude towards sexual rehabilitation. There is little information on the knowledge about, and attitude towards sexual rehabilitation of PWDs among OT practitioners in Nigeria. This study therefore assessed the knowledge and attitude of occupational therapy (OT) professionals and trainees about sexual rehabilitation of PWDs. Method: Using a purposive sampling technique, 73 OT professionals and trainees responded to this cross-sectional survey. Data obtained were analyzed using descriptive and inferential statistics. Significance level was set at 0.05. Results: The mean knowledge score for the OT trainees was $22.87 \pm 3.90$ and $23.44 \pm 4.84$ for OT professionals. Similarly, the mean score for attitude was $57.00 \pm 4.65$ for OT trainees and $56.24 \pm 6.94$ for OT professionals. Over $80 \%$ of the respondents had moderate knowledge about sexual rehabilitation while all the respondents had positive attitude towards sexual rehabilitation. Also, the attitude of OT professionals towards sexual rehabilitation of PWDs was significantly lower than that of the OT trainees ( $t=0.56 ; \mathrm{p}-0.009)$ (Table-3). In addition, there was significant correlation between the knowledge and attitude of the respondents towards sexual rehabilitation of PWDs $(\rho=0.26 ; p=0.025)$ (Table-4). Conclusion: In Nigeria, OT professionals and trainees demonstrated satisfactory knowledge and attitude about sexual rehabilitation of PWDs. Significant relationships exist between knowledge and attitude towards sexual rehabilitation of PWDs.

Keywords: occupational therapy professionals, occupational therapy trainees, knowledge, attitude, sexual rehabilitation, persons with physical disabilities (PWDs).

Copyright @ 2019: This is an open-access article distributed under the terms of the Creative Commons Attribution license which permits unrestricted use, distribution, and reproduction in any medium for non-commercial use (NonCommercial, or CC-BY-NC) provided the original author and source are credited.

\section{INTRODUCTION}

Sexuality is a fundamental aspect of health and well-being for all individuals, but it is often a difficult and sensitive subject to discuss, even in the most intimate relationships [1]. It becomes even more difficult to address in a setting such as a hospital or health care facility where interactions are more formal [1]. Sexual feelings and actions can cover a gamut of expressions such as holding hands, flirting, touching, kissing, masturbating, and having sexual intercourse [2]. Sexuality is expressed in all people - with or without disabilities [3]. Persons with disabilities (PWDs) are all persons who have long-term physical, mental, intellectual or sensory impairments that, in the face of various negative attitudes or physical obstacles, may prevent those persons from participating fully in society [4]. Physical disabilities, depending on the degree, often have associated sexual dysfunction [5]. As sexual activity is an activity of daily living (ADL) and defined in the Occupational Therapy Practice Framework [6], it falls under the scope of practice of all occupational therapists [2].

Studies have shown that resuming sexual activities is paramount for PWDs [5, 7]. For instance, Anderson [5] surveyed hundreds of individuals with spinal cord injury ( $\mathrm{SCI}$ ) to assess what priorities would most impact their quality of life (QoL). For the study population with quadriplegia, the author found that regaining sexual function was their highest priority after the recovery of arm and hand function. On the other hand, studies $[8,9]$ that have investigated the level of comfort that OT professionals and students had regarding sexual issues found that the OT students did not feel that they were knowledgeable and comfortable enough to address numerous sexuality issues. Patients 
deserve to be treated in a holistic manner which incorporates all aspects of the human life, including sexuality. The patients have stated the need; the occupational therapists have stated the legitimacy; so what is preventing the inclusion of sexuality in therapy? Could it be a lack of sexual rehabilitation knowledge or negative sexual attitude of the occupational therapist? Hence, it is argued that the knowledge and attitude of OT professionals and trainees about sexual rehabilitation of PWDs will affect whether and how they will deal with issues of sexuality during therapy [10].

There is a vast body of literature available on the sexual rehabilitation of PWDs [7-13], but there has been little study carried out on the involvement of sexuality in OT treatment, including the knowledge and attitude of the OT professionals and trainees surrounding these issues in Nigeria. There may be a time in an occupational therapist' career when these issues will arise and current students do not feel that they will be prepared to handle it appropriately [8]. Therefore, it was necessary for a study to be carried out to provide evidence for the need for OT personnel and students to be adequately educated in a more comprehensive manner regarding the sexual rehabilitation of PWDs. Owing to the dearth of studies on attitude and knowledge of OT professionals and trainees about sexual rehabilitation of PWDs, this study attempted to bring light to these issues to assist occupational therapists in providing the holistic care patients deserve. The outcome of this study may help to know areas of improvement in OT education on the sexual rehabilitation of PWDs.

\section{MATERIAL AND METHODS \\ Study Design}

This study used a cross-sectional study design.

\section{Study Setting}

The study was carried out at the south-west and south-south regions of Nigeria.

\section{Respondents}

Respondents of this study were occupational therapy professionals and baccalaureate occupational therapy trainees within the regions of the study setting.

\section{Sampling Technique}

A purposive sampling technique was used.

\section{Instrument}

The instrument for this study was a threesectioned self-administered questionnaire on knowledge and attitude about sexual rehabilitation. The first section of the questionnaire consisted of 11 questions eliciting demographic information such as age, gender, marital status, and years of study/experience. The second section used the sexual knowledge assessment developed by Stanger and colleagues [10] to explore the knowledge of respondents on sexual rehabilitation. The third section of the questionnaire used the Survey of Attitudes towards the Sexuality of Adults with Disabilities (SASAD) [9] to assess respondents' attitude towards sexuality of PWDs.

\section{Sexual knowledge assessment}

The sexual knowledge assessment tool (SKA) is a 35-item scale that uses binary options of true and false to explore the knowledge of individuals about sexuality. The number of correct responses to the items is used to compute the level of knowledge. A high score therefore correlated with a higher level of knowledge on sexuality. For the current study, the knowledge score was categorized into three levels which were poor (total score ranging from 1-15), moderate (total score ranging from 16-25) and good knowledge (total score ranging from 26-35).

\section{Survey of Attitudes towards the Sexuality of Adults with Disabilities}

This is a self-administered14-item questionnaire that assesses the attitudes of health professionals towards sexuality and disability rehabilitation on a five-point Likert scale. It has a total score ranging from 14 to 70 [10] and a higher score on the SASAD indicates a more positive attitude towards the sexual rehabilitation of PWDs. For our current study, the attitude scores were collapsed into two agree and strongly agree were merged, similarly, disagree and strongly disagree were merged. Finally, the attitude towards the sexuality of PWDs of respondents was categorized into two possible attitudes which were negative (scores $\leq 40$ ) and positive attitudes (scores> 40).

\section{Ethical Consideration}

Ethical approval for this study was obtained from the Ethical Review Committee of the Obafemi Awolowo University Teaching Hospital Complex.

\section{Procedure}

The purpose of the research was explained to the respondents and informed consent was obtained before participation. The copies of the questionnaire were manually distributed by the researcher and collected on spot or returned by correspondence.

\section{Data Analysis}

Data were summarized using descriptive statistics of mean, standard deviation, and frequency distribution. Similarly, inferential statistics of Pearson correlation was used to check the association between the attitude score and knowledge score of OT professionals and OT trainees on sexual rehabilitation of PWDs. T-test was used to check the difference in the attitude score between OT professionals and OT trainees on the sexual rehabilitation of PWDs and the difference in knowledge score between OT professionals and OT trainees on sexual rehabilitation 
of PWDs. The level of significance was set at $\alpha=0.05$. The data was managed using the Statistical Package for Social Sciences version 21.

\section{RESULTS AND DISCUSSION}

Seventy-three OT professionals and trainees that consist of 34 licensed OT registrants and 39 OT students responded to this study yielding a response rate of $81.1 \%$. The mean age of the respondents was 25.85 (S.D \pm 4.985$)$ with a range of $17-44$ years. It was noted that $90.4 \%$ of the respondents were within 17-30 years age bracket and this finding of higher percentage of young respondents may be connected to the fact that OT is still an evolving profession in Nigeria and as such younger therapists constitute the bulk of the profession's population. Furthermore, $69.9 \%$ of the respondents reported inclusion of sexual education in their OT curriculum. The 51 respondents who said sexual education was included in their training as an occupational therapist reported spending between one to four hours on the topic.
As in past studies [15-18], the respondents in this study were questioned on whether they felt that addressing sexuality was a role of occupational therapists and if they address it with their patients. The view of discussing sexuality issues with patients was believed to be a role for occupational therapists by 70 $(95.9 \%)$ respondents and some reasons supporting this view included these: "patients should be treated using an holistic approach," "OT deals with patients of both sexes, hence, its relevance in the profession," and "It's an important part of ADLs and OT profession strongly addresses that." Nevertheless, three (4.1\%) respondents declined and said "it's against the ethics of the profession." Only $65.8 \%$ of respondents reported actually addressing sexuality with patients out of the $95.9 \%$ of respondents who believed addressing sexuality issues with patients is a role for OT. Percentage of day spent with patients with physical disabilities ranged from $12.5 \%$ to $85.0 \%$ $(X=31.38 \pm 15.95)$ and the years of service with PWDs ranged from one to nine years $(X=3.05 \pm 2.06)$.

Table-1: Knowledge of sexuality of persons with disabilities among occupational therapy professionals and trainees

\begin{tabular}{|c|c|c|}
\hline Knowledge Questions & $\begin{array}{l}\% \text { of correct } \\
\text { responses } \\
\mathrm{N}(\%)\end{array}$ & $\begin{array}{l}\text { Correct } \\
\text { Answers }\end{array}$ \\
\hline 1.Autoeroticism is sexual self-stimulation, for example, masturbation & $66(90.4)$ & True \\
\hline $\begin{array}{l}\text { 2. A violent home environment and a hostile masculine personality are two factors that predispose } \\
\text { men to engage in sexual coercion of women }\end{array}$ & $49(67.1)$ & True \\
\hline 3. Herpes simplex virus 1 cannot be transmitted to the genitals during oral genital sex & $55(75.3)$ & False \\
\hline $\begin{array}{l}\text { 4. About } 50 \% \text { of women with spinal cord injuries are able to have orgasms from stimulation of } \\
\text { genitals }\end{array}$ & $37(50.7)$ & True \\
\hline 5. Dysmenorrhea is defined as painful menstruation & $59(80.8)$ & True \\
\hline 6. Available data does not point to any single factor as a cause of homosexuality & $55(75.3)$ & True \\
\hline 7. Only men are capable of having multiple orgasms & $58(79.5)$ & False \\
\hline 8. Today the majority of Nigerians approve of extramarital sex & $36(49.3)$ & False \\
\hline 9. A transsexual is a person who believes he/she is trapped in the body of the other gender & $53(72.6)$ & True \\
\hline 10. Hypothalamus, pituitary glands and gonads all influence sexual behavior & $61(83.6)$ & True \\
\hline 11. About one out of five stranger rapes are reported to the police & $48(65.8)$ & True \\
\hline 12. Birth control pills work mainly by preventing ovulation & $51(69.9)$ & True \\
\hline 13. Most divorced women, but fewer widowed women, return to having an active sex life & $37(50.7)$ & True \\
\hline 14. For most children, the major source of sex information is the mother & $38(52.1)$ & False \\
\hline 15. Erection in a male is produced by a simple spinal reflex & $45(61.6)$ & True \\
\hline 16. Female genital cutting is no longer a worldwide sexual health controversy & $30(41.1)$ & False \\
\hline 17. The majority of women do not continue to engage in sexual activity after menopause & $46(63.0)$ & False \\
\hline 18. Approximately $80 \%$ of breast lumps are benign & $56(76.7)$ & True \\
\hline $\begin{array}{l}\text { 19. For severe cases of erectile disorder, surgery can be performed to implant prosthesis into the } \\
\text { penis }\end{array}$ & $48(65.8)$ & True \\
\hline $\begin{array}{l}\text { 20. At least } 2 / 3 \text { of parents and high school students support programs which make condoms } \\
\text { available in schools }\end{array}$ & $31(42.5)$ & False \\
\hline 21. Masturbation is rare among married adults & $38(52.1)$ & False \\
\hline 22. Sex hormones are manufactured by endocrine glands & $59(80.8)$ & True \\
\hline 23. Pheromones are biochemicals secreted outside the body that may serve a role as sex attractants & $55(75.3)$ & True \\
\hline $\begin{array}{l}\text { 24. There are two strains of the HIV virus, although one of them is found almost exclusively in } \\
\text { Africa }\end{array}$ & $51(69.9)$ & True \\
\hline 25. In general, the frequency of marital intercourse declines with age & $60(82.2)$ & True \\
\hline 26. Vaginal deliveries are not possible for pregnant women with spinal cord injuries & $25(34.2)$ & False \\
\hline $\begin{array}{l}\text { 27. By age seven, } 30 \% \text { of Nigerian children understand genital differences between male and } \\
\text { female }\end{array}$ & $53(72.6)$ & True \\
\hline 28. The majority of men with spinal cord injury are unable to have an ere & $26(35.6)$ & False \\
\hline
\end{tabular}




\begin{tabular}{|l|l|l|}
\hline 29. Many Africans see AIDS as a planned strategy to kill Africans & $38(52.1)$ & True \\
\hline $\begin{array}{l}\text { 30. Many medications used to treat erectile dysfunction (e.g.,Viagra) are not recommended for men } \\
\text { who take medication for a heart condition }\end{array}$ & $64(87.7)$ & True \\
\hline $\begin{array}{l}\text { 31. During menopause women are no more vulnerable to infection than women who are not } \\
\text { experiencing menopause }\end{array}$ & $30(41.1)$ & False \\
\hline $\begin{array}{l}\text { 32. Condoms and vasectomy are two highly effective methods of birth control that can be used by } \\
\text { men }\end{array}$ & $67(91.8)$ & True \\
\hline $\begin{array}{l}\text { 33. Hepatitis B is more common than most people think because it receives relatively little publicity } \\
\text { compared with AIDS and herpes }\end{array}$ & $61(83.6)$ & True \\
\hline $\begin{array}{l}\text { 34. Untreated gonorrhea can lead to sterility in women } \\
\text { 35. Testicular cancer is rare in men }\end{array}$ & $60(82.2)$ & True \\
\hline
\end{tabular}

Table-1 shows that the questions with the highest correct responses were: 1 (90.4\%), 32 (91.8), and 30 (87.7). Based on the categorization of knowledge score into three levels of poor, moderate, and good knowledge, $82.2 \%$ respondents had average knowledge while $17.8 \%$ respondents had good knowledge. The highest possible score was a 35 on the SKA and the mean knowledge score for the respondents was 22.87 (S.D \pm 3.90 ). This is a decrease in score obtained by Stanger et al., [10]. This finding was also in contrast to those of some authors, such as Jones et al.,
[8] and Penna et al., [15], where results indicated a lack of knowledge in the area of sexuality. From this study, $90.4 \%$ of the respondents knew that condoms and vasectomy are two highly effective methods of birth control that can be used by men. This finding is in tandem with previous study [10] among occupational therapists in Ohio, where the authors reported similar findings. Also, majority of the respondents knew that in general, the frequency of marital intercourse declines with age, which is also similar to previous findings [10].

Table-2: Occupational therapy professionals' and trainees' attitude toward sexual rehabilitation of persons with disabilities

\begin{tabular}{|c|c|c|c|c|}
\hline Attitude questions & $\begin{array}{l}\text { Agree } \mathbf{N} \\
(\%)\end{array}$ & $\begin{array}{l}\text { Indifferent } \\
\mathbf{N}(\%)\end{array}$ & $\begin{array}{l}\text { Disagree } \\
\mathbf{N}(\%)\end{array}$ & Comment \\
\hline $\begin{array}{l}\text { 1. Sexuality is an important dimension of health care and rehabilitation } \\
\text { process }\end{array}$ & $66(90.4)$ & $7(9.6)$ & $0(0)$ & Positive \\
\hline $\begin{array}{l}\text { 2. Sexuality and sex drive remain intact, although physical disability or } \\
\text { chronic illness may impose alterations in sex acts }\end{array}$ & $52(71.2)$ & $16(5)$ & $5(6.8)$ & Positive \\
\hline $\begin{array}{l}\text { 3. In assessing a patient for activities of daily living, all aspects should be } \\
\text { considered: physical, vocational, recreational, as well as sexual }\end{array}$ & $73(100.0)$ & $0(0)$ & $0(0)$ & Positive \\
\hline $\begin{array}{l}\text { 4. In evaluating an adult who is chronically ill or disabled for activities of } \\
\text { daily living, therapists should ask routine questions concerning the patient's } \\
\text { sexual history }\end{array}$ & $62(85)$ & $7(9.6)$ & $4(5.4)$ & Positive \\
\hline $\begin{array}{l}\text { 5. Probing into the sex lives of a person who is disabled would be a source of } \\
\text { irritation or embarrassment }\end{array}$ & $24(32.8)$ & $26(35.7)$ & $23(31.5)$ & Indifferent \\
\hline $\begin{array}{l}\text { 6. History taking and discussions of sexuality should be done within the } \\
\text { context of the patient's total problem }\end{array}$ & $52(71.2)$ & $13(17.8)$ & $8(11.0)$ & Positive \\
\hline 7.Sexual rehabilitation should not be encouraged in the hospital & $15(20.5)$ & $11(15.1)$ & $47(64.4)$ & Positive \\
\hline 8. Information on sexuality should be made available to patients & $63(86.3)$ & $4(5.5)$ & $6(8.2)$ & Positive \\
\hline $\begin{array}{l}\text { 9. Patients in OT have questions related to sexuality and their disability or } \\
\text { illness }\end{array}$ & $42(57.6)$ & $16(21.9)$ & $15(20.5)$ & Positive \\
\hline $\begin{array}{l}\text { 10. Medical aspects of sexuality should be integrated into the basic OT } \\
\text { curricula of schools }\end{array}$ & $62(85.0)$ & 7 (9.6) & $4(5.4)$ & Positive \\
\hline $\begin{array}{l}\text { 11. Rehabilitation team members should try discussing sexuality and sexual } \\
\text { functioning with patients who have disabilities or a chronic illness and with } \\
\text { colleagues }\end{array}$ & $50(68.5)$ & $13(17.8)$ & $8(13.7)$ & Positive \\
\hline $\begin{array}{l}\text { 12. Occupational therapists should not become involved in the sexual aspects } \\
\text { of rehabilitation of patients with disabilities }\end{array}$ & $8(11.0)$ & $2(2.7)$ & $63(86.3)$ & Positive \\
\hline $\begin{array}{l}\text { 13. Occupational therapists should leave the discussion of sexuality to other } \\
\text { rehabilitation team members }\end{array}$ & $2(2.7)$ & $8(11.0)$ & $63(86.3)$ & Positive \\
\hline $\begin{array}{l}\text { 14. Most occupational therapists do not know enough about the medical } \\
\text { aspects of sexuality and sexual functioning }\end{array}$ & $18(24.6)$ & $27(37.0)$ & $28(38.4)$ & Positive \\
\hline
\end{tabular}

The result in Table- 2 revealed that all of the respondents had positive attitude towards the sexual rehabilitation of PWDs. This is consistent with the findings of previous studies $[9,10,13,16]$ that explored the attitude of rehabilitation personnel on sexual rehabilitation. This finding suggests that the attitude of occupational therapists towards the sexuality of PWDs has remained consistent over the years. It was found that respondents with more positive attitudes on the SASAD [11] were more likely to believe that addressing sexuality was a role for OT and were also more likely to address it with their patients. Even 
though this study indicates that occupational therapists had positive attitude towards sexual rehabilitation, and believe sexual rehabilitation as an important role for OT during the rehabilitation of PWDs, many are still not addressing it. This is in tandem with the findings of Penna and Kieron [13].

Table-3: Knowledge and attitude scores of occupational therapy professionals and trainees

\begin{tabular}{|l|l|l|l|l|l|l|l|l|}
\hline Variable & \multicolumn{3}{|c|}{ OT Professionals } & \multicolumn{3}{c|}{ OT Trainees } & \multicolumn{2}{l|}{} \\
\hline & Mean \pm SD & Min & Max & Mean \pm SD & Min & Max & t-test & p-value \\
\hline Attitude & $56.2 \pm 6.9$ & 45.0 & 68.0 & $57.0 \pm 4.7$ & 45.0 & 64.0 & $0.56^{*}$ & 0.009 \\
\hline Knowledge & $23.4 \pm 4.8$ & 16.0 & 34.0 & $22.9 \pm 3.9$ & 17.0 & 31.0 & -0.56 & 0.748 \\
\hline
\end{tabular}

Table-3 shows the distribution of knowledge and attitude of the respondents on sexual rehabilitation of PWDs. The mean knowledge score of the OT students was 22.87 (range $=17.0$ to 31.0 ) while the mean knowledge score of occupational therapists was 23.44 (range $=16.0$ to 34.0 ). The mean attitude score of the OT professionals towards sexual rehabilitation of PWDs was significantly lower than that of the OT trainees $(\mathrm{t}=0.56 ; \mathrm{p}-0.009)$ (Table-3). In addition, there was significant correlation between the knowledge and attitude of the respondents towards sexual rehabilitation of PWDs $(\rho=0.26 ; p=0.025)$ (Table-4).

Table-4: Relationship between knowledge and attitude of the respondents towards sexual rehabilitation of PWDs

\begin{tabular}{|l|l|l|}
\hline & Spearman correlation matrix ( $(\rho)$ & Sig. level \\
\hline Knowledge*Attitude & 0.26 & 0.025 \\
\hline
\end{tabular}

\section{CONCLUSION AND RECOMMENDATIONS}

Occupational therapy professionals and trainees practicing in south western and south-southern states in Nigeria demonstrated satisfactory knowledge about, and positive attitudes towards sexual rehabilitation of PWDs. Even though, addressing sexuality of PWDs was identified as an important role for OT, this was seldom carried out.

These results suggest that occupational therapists in Nigeria should incorporate sexuality in their modality for holistic care and comfort of the patients as desired. Also, there is a need for occupational therapists to be regularly updated with relevant knowledge on sexual rehabilitation. Increased sexual rehabilitation knowledge may contribute to reinforcing the positive attitude of occupational therapists and OT students on sexual rehabilitation of PWDs. Finally, occupational therapists need the knowledge of sexual rehabilitation to practice. Increased knowledge can be achieved by engaging in continuous professional development activities related to sexual rehabilitation, keeping abreast of recent research in sexual rehabilitation, and the inclusion of sexuality into the curriculum of OT programs. The knowledge and attitude scores support this role for occupational therapists but still it is not being addressed by all. The development of a practice guideline for occupational therapists in Nigeria could facilitate uniformity in service delivery among OT professions and ensure that our patients receive the holistic care they deserve.

\section{REFERENCES}

1. Esmail, S., Knox, H., \& Scott, H. (2010). Sexuality and the Role of the Rehabilitation Professional. Center for International Rehabilitation Research Information and Exchange, 1-17.
2. MacRae, N. (2013). Sexuality and the Role of Occupational Therapy Fact Sheet. American Occupational Therapy Association, 1-2.

3. Dicker-Friedman, J. (1997). Sexual expression: The forgotten component of ADL. OT Practice, 2(1), 20-25.

4. Functioning and Disability Reference Group. (2010). The ICF: An Overview. World Health Organization, 1-10.

5. Anderson, K. (2004). Targeting recovery: Priorities of the spinal cord injured population. Journal of Neurotrauma, 21(10), 1371-1383.

6. American Occupational Therapy Association, (2008). Occupational therapy practice framework: Domain \& process (2nd Ed.) American Journal of Occupational Therapy, 62, 625-683.

7. Leibowitz, R. Q. (2005). Sexual rehabilitation services after spinal cord injury: What do women want? Sexuality and Disability, 23, 81-107.

8. Jones, M. K., Weerakoon, P., \& Pynor, R. A. (2005). Survey of occupational therapy students' attitudes toward sexual issues in clinical practice. Occupational Therapy International, 12(2), 95106.

9. Guest, K. L., \& Kopp, B. (1997). The development of the survey of attitudes toward sexuality of adults with disabilities. Topics in Geriatric Rehabilitation, 12(4), 61-71.

10. Stanger, N. L., \& Miller, B. K. (2009). Sexual Attitudes of Occupational Therapists Regarding Persons with Physical Disabilities: A Follow-up Study. University of Toledo.

11. Ahumuza, S. E., Matovu, J. K., Ddamulira, J. B., \& Muhanguzi, F. K. (2014). Challenges in accessing sexual and reproductive health services by people with physical disabilities in Kampala, Uganda. Reproductive health, 11(1), 59.

12. Shakespeare, T. (2000). Disabled Sexuality: Toward Rights and Recognition. Sexual Disability, 
$18,159-166$.

13. Layte, R., Williams, J., Quail, A., \& McGee, H. (2005). Scoping study for knowledge, attitudes and behaviours survey towards relationships, sexual and reproductive health among young people in Ireland.

14. Shipley, H. J., \& DeLamater, J. D. (2000). Understanding human sexuality (7th Ed.). Boston: McGraw-Hill.

15. Penna, S., \& Kieron, S. (2000). Sex education and schizophrenia: Should occupational therapists offer sex education to people with schizophrenia? Scandinavian Journal of Occupational Therapy, 7 , 126-131.

16. Conine, T. A., Christie, G. M., Hammond, G. K.,
\& Smith, M. F. (1979). An assessment of occupational therapists' roles and attitudes toward sexual rehabilitation of the disabled. American Journal of Occupational Therapy, 33(8), 515-519.

17. Conine, T. A. (1984). Sexual rehabilitation: the roles of allied health professionals. In: Kreuger, D. W., editor. Rehabilitation psychology: A comprehensive textbook, Rockville, Maryland: Aspen Systems Corp.

18. Esmail, S., Esmail, Y., \&Munro, B. (2001). Sexuality and disability: The role of health care professionals in providing options and alternatives for couples. Sexuality and Disability, 19(4):267282. 